\title{
Scaling of speed and endurance in garter snakes: a comparison of cross-sectional and longitudinal allometries
}

\author{
BRUCE C. JAYNE \\ Department of Developmental and Cell Biology, University of California, Irvine, CA 92717. \\ USA
}

\author{
AND A. F. BENNETT \\ School of Biological Sciences, Unicersity of California, Irvine, CA 92717, USA
}

(Accepted 17 May 1989)

(With 5 figures in the text)

This study used cross-sectional (one observation per each of several individuals of different size) and longitudinal (more than one observation through time per individual) methods to determine the effects of size on speed and endurance of Thamnophis sirialis fitchi. The cross-sectional sample consisted of 497 snakes from a single population. Log of mean burst speed in this group measured over $50 \mathrm{~cm}$ (V50) was a quadratic function of log of snout-vent length (SVL); the slope of this polynomial ranged from about 1.6 to -0.3 for the smallest to the largest snakes (maximal $V 50$ at $50.6 \mathrm{~cm} \mathrm{SVL}$ ). Longitudinal measurements of $\log V 50$ also were quadratically related to $\log \mathrm{SVL}$, but the slopes varied depending on year in which performance was measured. Cross-sectional allometry revealed that the slope of the regression relating $\log (e n d u r a n c e)$ to $\log (\mathrm{SVL})$ was about $2 \cdot 3$, and longitudinal estimates of this quantity ranged from 0.5 to $3 \cdot 2$, depending on the year. Sex did not affect burst speed, but females had significantly less endurance than males of equal SVL, and pregnancy had a significant detrimental effect on both speed and endurance. Regressions with SVL as the independent variable were used to generate size-corrected (residual) values of speed, endurance and mass, and each of these residuals had significant repeatability. For example, during 1986 the short-term repeatabilities (Pearson's $r$ ) of speed and endurance residuals were $0.65(P<0.001)$ and $0.57(P<0.001)$. From 1986 to 1987 , year-to-year repeatabilities of speed, endurance and mass residuals were $0.25(P=0.001), 0.22(P=0.005)$ and $0.47(P<0.001)$, respectively. Analysis of these three respective residual values of 264 neonatal snakes from 34 litters revealed highly significant percent variance components attributable to litter of $14 \%, 34 \%$ and $36 \%$, yielding respective heritabilities of $0.28,0.68$ and 0.72 . Speed and endurance residuals had a low but significant positive correlation $(r=0 \cdot 26, n=497)$, due apparently to snakes with poor performance: high speed is not linked with high endurance. A squared value of the mass residual had a significant negative correlation with both speed residual $(r=-0 \cdot 105, n=497)$ and endurance residual $(-0.24)$, suggesting that snakes deviating from a mean value of mass relative to length have a slight decrement in locomotor performance. Longitudinal estimates of the scaling of mass with length revealed significant variation associated with different ages of snakes and different years of the study that could not be obtained from cross-sectional data.

\section{Contents}

$\begin{array}{llllllllllllllllll}\text { Introduction } & \ldots & \ldots & \ldots & \ldots & \ldots & \ldots & \ldots & \ldots & \ldots & \ldots & \ldots & \ldots & \ldots & \ldots & \ldots & \ldots & 258 \\ \text { Material and methods } & \ldots & \ldots & \ldots & \ldots & \ldots & \ldots & \ldots & \ldots & \ldots & \ldots & \ldots & \ldots & \ldots & \ldots & 259 \\ \text { Subjects .. } & \ldots & \ldots & \ldots & \ldots & \ldots & \ldots & \ldots & \ldots & \ldots & \ldots & \ldots & \ldots & \ldots & \ldots & \ldots & \ldots & 259 \\ \text { Performance testing and analysis } & & \ldots & \ldots & \ldots & \ldots & \ldots & \ldots & \ldots & \ldots & \ldots & \ldots & \ldots & 259\end{array}$




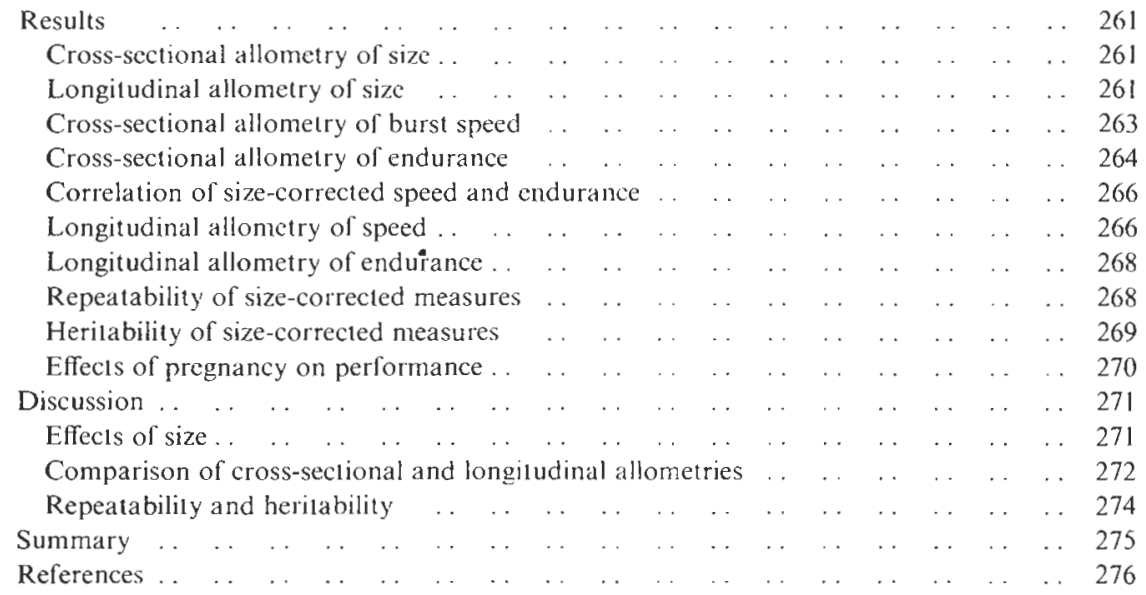

\section{Introduction}

A recurrent finding of biological studies is that size of animals has pervasive effects on morphology and function (for reviews see Schmidt-Nielsen, 1984; Calder, 1984), and locomotion is one of the many functions for which the effects of size have been examined in detail (Pedley, 1977; McMahon, 1984). To obtain a wide range of animal size, many studies of locomotor function have relied on interspecific comparisons (e.g. Taylor, Heglund \& Maloiy, 1982; Alexander, 1985). Although considerable insight can be gained from such interspecific studies, there are potentially many factors other than size that may confound their interpretation (Cheverud, 1982). Fewer studies have determined the effects of size on locomotion by studying individuals of different age (and size) within a species (e.g. fish: Brett \& Glass, 1973; amphibians: Taigen \& Pough, 1981; snakes: Pough, 1978; lizards: Garland, 1985). Such studies of intraspecific allometric effects have usually relied on 'cross-sectional' sampling (one observation per each of many individuals of different size) rather than longitudinal sampling (more than one observation per individual at different times). Depending on the extent of selection and other factors affecting natural populations, different scaling relationships might be found by using these two different sampling methods. For instance, strong directional selection for speed and differential death of slow animals would cause an apparently greater size dependence in a cross-sectional analysis than in a longitudinal one. Presently, no single study has examined and compared the cross-sectional and longitudinal approaches to the analysis of size dependence of locomotor ability in any single population of animals.

In many respects, reptiles and other lower vertebrates are ideally suited for studying intraspecific allometry of locomotion. The combination of indeterminate growth and offspring that are ambulatory upon birth or hatching provides an enormous range of size over which locomotion can be studied. For example, in crocodilians there may be a 20 -fold increase in snoutvent length and more than 10000-fold increase in mass from hatchlings to large adults (Webb \& Messel, 1978). In the garter snake Thamnophis sirtalis, we have found that large adults may have a five-fold greater snout-vent length and a 100 -fold greater mass than neonatal snakes. For snakes, the large ontogenetic size range and manageable maximum size of many species greatly facilitates intraspecific allometric studies of locomotor performance within a population. Heckrotte (1967) made one of the first systematic attempts to examine the effects of size on the speed of snakes. For 
garter snakes crawling past a series of pegs, Heckrotte (1967) found that the speed of locomotion increased with size of the snake up to some optimal size and then decreased with further size increments. Subsequent studies that have determined speeds within a single species of snake often have had variable testing conditions (Hailey \& Davies, 1986), small sample sizes (Jayne, 1985) or a limited size range of individuals (Stevenson, Peterson \& Tsuji, 1985; Garland, 1988; Arnold \& Bennett, 1988). Because of this diversity of sampling and testing methodology, it is not too surprising that these previous studies have variously found that there is no effect (Stevenson et al., 1985), a small effect (Garland, 1988; Arnold \& Bennett, 1988) or a large effect (Heckrotte, 1967; Jayne, 1985) of size on the locomotor performance of snakes.

In view of the paucity of studies that have either systematically determined locomotor performance or its scaling relationships for limbless vertebrates, we examined the scaling relationships of locomotion as part of a larger study dealing with survivorship and demographics of a population of snakes. This study used speed and endurance as measures of locomotor performance for individuals ranging from neonatal animals to large adults from a single natural population of the garter snake, Thamnophis sirtalis fitchi. Both cross-sectional and Iongitudinal sampling methods were used to determine the scaling relationships of locomotor performance with size, and the results of these two methods were compared. Repeatability and heritability of size-corrected values of locomotor performance were calculated. The effect of distance on the measurement error and scaling relationship of burst speed was determined, as well as the effect of pregnancy on locomotor performance.

\section{Materials and methods}

\section{Subjects}

We studied individuals from a single population of Thamnophis sirtalis fitchicollected from a single pond in Lassen County in Northern California, USA (California scientific collecting permit number 485). Crosssectional allometries were calculated from tests of 497 non-gravid snakes collected during June through August 1986. To obtain performance data from the widest possible size range for the cross-sectional analysis, this sample of non-gravid snakes included 49 neonatal snakes born to snakes that were collected and then maintained in captivity for about 1 month before parturition. To determine the effect of pregnancy on performance 15 gravid snakes were also tested during 1986. Figure 1 illustrates the frequency distribution of the size of the non-gravid snakes used for the cross-sectional analysis.

All snakes were given a unique and permanent identification mark consisting of clipped ventral scales before their release, allowing us to obtain longitudinal information on locomotor performance of many individuals during the successive years of the study (1985-1988). During 1985 we tested locomotor performance and then released 275 offspring from 40 females that were temporarily held in captivity. Hence, the age of these 275 snakes was known unambiguously, and samples consisting only of these snakes will subsequently be referred to as ' 1985 cohort' samples, whereas samples including all snakes collected during a given time period will be referred to as 'population' samples. At least one type of performance test was performed on 483 individuals during 1987 and 284 indjviduals during 1988. Greater detail of sample sizes is presented in the results of the longitudinal analysis.

\section{Performance testing and analysis}

Within 3 days of birth or capture we began a series of tests of locomotor performance. All tests were conducted on snakes with a body temperature of $30^{\circ} \mathrm{C}\left(\right.$ range $\left.= \pm 1.0{ }^{\circ} \mathrm{C}\right)$, the temperature at which these 


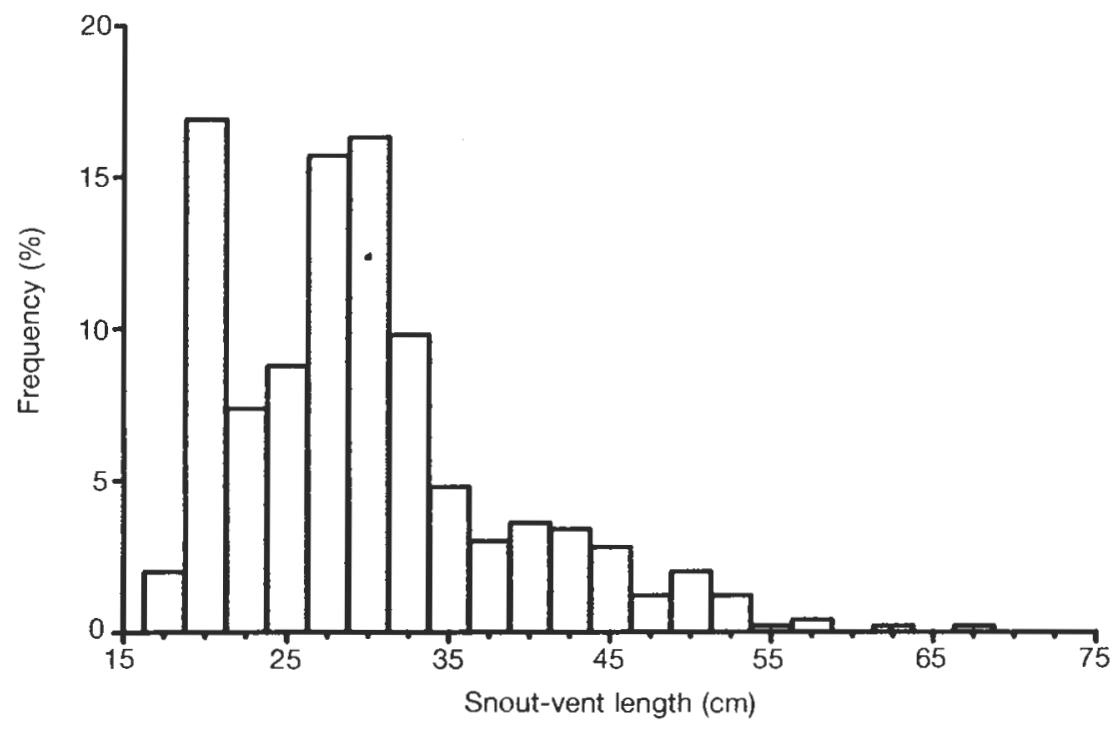

FIG. 1. Frequency distribution of the snout-vent lengths for the 497 snakes captured and tested during 1986 for the calculation of cross-sectional allometries.

animals are normally active under field conditions. Tests were performed during daylight hours between 08:00 and 20:00 h. All snakes were kept in individual containers to minimize handling and allow identification of individuals during the tests. After performance testing and before release of the snakes at the site of capture, all snakes were uniquely marked by cut ting ventral scales; snout-vent and tail lengths were measured to the nearest millimetre and mass was determined to the nearest $0.1 \mathrm{~g}$.

A racetrack similar in overall design to that of Huey, Schneider \& Stevenson (1981) was used to determine burst speed. The bottom of the track was lined with artificial grass turf, and a preliminary analysis (using the methods of Jayne, 1986) of 16-mm cine films taken of snakes indicated that this surface was good for facilitating rapid lateral undulatory locomotion. The length of the track was $3 \mathrm{~m}$ and lights and photodetectors were spaced at $25-\mathrm{cm}$ intervals along the middle $2 \mathrm{~m}$. The width of the track was $10 \mathrm{~cm}$ for most snakes, but it was changed to $15 \mathrm{~cm}$ for the largest animals so that lateral undulatory rather than concertina locomotion would be performed by the snakes. The photodetectors of the track were connected to an amplifier that was interfaced to an IBM XT computer via a Metra-Byte digital card. A signal generator used to test the amplifying circuitry and controlling computer programs verified that time differences of $1 \mathrm{~ms}$ could be detected.

A custom-built treadmill was used for the endurance tests. The effective tread area was $20 \times 80 \mathrm{~cm}$, with the longer direction being parallel to the movement of the tread surface. The belt of the treadmill was a rubberimpregnated cloth covered with $2 \times 5 \mathrm{~cm}$ strips of friction tape ( $3 \mathrm{M}$ medium duty 7740 antislip safety walk). The 1-mm thickness of the friction tape combined with some curling of the edges of each strip provided sufficient surface irregularities so that the snakes readily performed lateral undulatory locomotion.

Burst speed $( \pm 1 \mathrm{~mm} / \mathrm{s})$ was determined on days 1 and 2 of testing by conducting 2 replicates in rapid succession for both a morning and afternoon trial on each of these 2 days. Snakes were encouraged to crawl at maximal speed by rapidly tapping either the substratum behind the snake or the snake's tail as it crawled. The snakes had at least $3 \mathrm{~h}$ of recovery between morning and afternoon trials. For each pair of replicates within a trial, the fastest speed over a continuous $50-\mathrm{cm}$ interval was determined, and these values were averaged for the 4 trials to yield a single estimate of burst speed for each individual. For snakes tested during 1986, mean burst speeds were also calculated for their fastest 25,75 and $100-\mathrm{cm}$ intervals. 
Endurance was determined as the time $( \pm 0.01 \mathrm{~min})$ that an animal maintained $0.5 \mathrm{~km} / \mathrm{h}$ on the treadmill with one trial per snake on both days 3 and 4 of testing. After preliminary trials using tread speeds of $0 \cdot 3,0 \cdot 4$, 0.5 and 0.6 , we chose $0.5 \mathrm{~km} / \mathrm{h}$ as a compromise between the best speed for maximizing variance among equalsized individuals and a speed that exhausted the largest individuals in a reasonable time (greatest observed time $=156 \mathrm{~min}$ ). Snakes usually crawled spontaneously on the treadmill, but occasionally, the tail of a snake had to be tapped lightly to prompt continued crawling. The end of a trial was determined as the time at which the snake fell off the treadmill by failing to match its speed 3 times in rapid succession ( $20 \mathrm{~s}$ ). For each snake, the mean of the 2 endurance trials was used for statistical analysis.

Most statistical analyses were performed using the PC + microcomputer version of SPSS. Throughout this paper all logarithmic transformations referred to are in base 10 , and all regressions were calculated by the least squares method. Unless otherwise stated $P<0.05$ was used as the decision criterion for determining significance. 'Residual (size-corrected)' refers to values that were calculated as the difference between an observed value and a predicted value from a regression equation.

To caiculate longitudinal allometric relationships, pairs of observations for each individual were used to estimate the slope of the scaling relationship in the following manner. To minimize the influence of errors in measuring size, pairs of observations were used to calculate longitudinal allometries only if there were minimal increases of both $1 \mathrm{~cm}$ in SVL and $1 \mathrm{~g}$ in mass or a $5 \%$ increase for these quantities, whichever was smaller. For an initial (i) and final (f) point in time, the observed values of the variables were log transformed, and slope of the scaling relationship for each individual was calculated as:

$$
\left(\log \left(\text { variable }_{f}\right)-\log \left(\text { variable }_{i}\right)\right) /\left(\log \left(\text { size }_{f}\right)-\log \left(\text { size }_{i}\right)\right)
$$

The mean of these values for each time or size group was then used as a longitudinal estimate of the allometric relationship over a given time period for all the individuals comprising a sample, such as those tested in 1986 and 1987. Two-tailed $t$-tests of the difference between 2 means were calculated according to the procedures given by Steele \& Torrie (1980).

\section{Results}

\section{Cross-sectional allometry of size}

Table I summarizes the scaling equations relating mass and total length (TL) to snout-vent length (SVL). The body proportions of males and females differ as indicated by a multiple regression with a highly significant $(P<0.0001)$ coefficient for a coded $(1=$ male, $2=$ female) variable for sex $\left(\log (\mathrm{mass})=-3.389+2.924 \log (\mathrm{SVL})+0.030 \mathrm{sex}, r^{2}=0.979\right)$. This regression indicated females were usually more massive than males of a given snout-vent length. For snakes with complete tails, Table I lists the regression equation for $\log (\mathrm{TL})$ as function of $\log (\mathrm{SVL})$ for males and females combined. For the 445 snakes with complete tails, females had significantly shorter total length than males of equal snout-vent length $(\log (\mathrm{TL})=0 \cdot 125+1 \cdot 007 \log (\mathrm{SVL})$ -0.007 sex, $r^{2}=0.997$ ). Although the effects of sex on body proportions are highly significant, a comparison of these $r^{2}$ values for multiple regressions including sex with those of regressions using only SVL indicates that sex is accounting only for a very small additional portion of the variance in mass and TL.

\section{Longitudinal allometry of size}

Table II summarizes the longitudinal estimates of the scaling relationship between mass and SVL. Mean estimates of the slope of $\log$ (mass) versus $\log (\mathrm{SVL})$ ranged from about $2 \cdot 4$ to $5 \cdot 1$, and there were significant differences in rate of gain of mass with gain in SVL depending on the year of 
TABLE I

Least squares regression statistics for scaling equations of size and locomotor performance in the form: $y=a_{0}+a_{1} x+a_{2} x^{2}$. Pooled indicates that dat a were combined for both sexes. $T L$ and $S V L$ are total and snout-vent lengths in $\mathrm{cm}$. For pooled samples, SVL ranged from $16.6-67.5 \mathrm{~cm}$ and mass range was $1 \cdot 5-104 \cdot 5 \mathrm{~g} . \mathrm{V} 25, \mathrm{~V} 50, \mathrm{~V} 75$ and VIOO are burst speeds in $\mathrm{cm} / \mathrm{smeasured} \mathrm{over} 25$. 50,75 and $100 \mathrm{~cm}$, respectively. ET and ED are endurance time (min) and endurance distance (m). See text for nore detail

\begin{tabular}{|c|c|c|c|c|c|c|c|}
\hline$y$ & Sample & $x$ & $n$ & $a_{0}$ & $a_{1}$ & $a_{2}$ & $r^{2}$ \\
\hline \multicolumn{8}{|c|}{ Size interrelations } \\
\hline $\log$ (mass) & pooled & $\log (\mathrm{SVL})$ & 497 & $-3 \cdot 349$ & 2.928 & - & 0.977 \\
\hline $\log (\mathrm{TL})$ & pooled & $\log (S V L)$ & 445 & 0.113 & 1.007 & - & 0.997 \\
\hline \multicolumn{8}{|c|}{ Size dependence of burst speed } \\
\hline $\log (\sqrt{ } 25)$ & poolcd & $\log (S V L)$ & 497 & $-4 \cdot 346$ & $7 \cdot 574$ & $-2 \cdot 254$ & 0.865 \\
\hline $\log (V 50)$ & pooled & $\log (\mathrm{SVL})$ & 497 & $-3 \cdot 766$ & $6 \cdot 730$ & -1.975 & 0.854 \\
\hline $\log (V 75)$ & pooled & $\log (\mathrm{SVL})$ & 497 & $-3 \cdot 684$ & 6.615 & -1.947 & 0.832 \\
\hline $\log (V 100)$ & pooled & $\log (S V L)$ & 497 & $-3 \cdot 762$ & 6.706 & -1.980 & 0.821 \\
\hline $\log (V 50)$ & SVL $<35$ & $\log (\mathrm{SVL})$ & 405 & -0.062 & $1 \cdot 310$ & - & 0.846 \\
\hline $\log (/ / 50)$ & pooled & $\log (\mathrm{TL})$ & 497 & $1 \cdot 343$ & $0 \cdot 770$ & -0.238 & 0.836 \\
\hline $\log (V 50)$ & pooled & $\log$ (mass) & 497 & $-4 \cdot 476$ & $7 \cdot 038$ & -1.921 & 0.853 \\
\hline \multicolumn{8}{|c|}{ Size dependence of endurance } \\
\hline $\log (\mathrm{ET})$ & pooled & $\log (\mathrm{SVL})$ & 497 & $-2 \cdot 439$ & $2 \cdot 284$ & - & 0.573 \\
\hline $\log (\mathrm{ET})$ & SVL $<35$ & $\log (\mathrm{SVL})$ & 405 & $-2 \cdot 451$ & $2 \cdot 295$ & & 0.442 \\
\hline $\log (\mathrm{ET})$ & pooled & $\log (T L)$ & 497 & $-2 \cdot 738$ & $2 \cdot 299$ & - & 0.573 \\
\hline $\log (\mathrm{ET})$ & pooled & $\log$ (mass) & 497 & 0.203 & 0.746 & - & 0.536 \\
\hline $\log (E D)$ & pooled & $\log (S V L)$ & 497 & -1.518 & $2 \cdot 284$ & - & 0.573 \\
\hline
\end{tabular}

\section{TABLE II}

Longitudinal estimates (mean) of $a_{1}$, the slope of the scaling equation $\log ($ mass $)=a_{1}{ }^{*} \log (S V L)$. Initial and final refer to the first and second points in time for which measurentents were made. $n=$ sample size, $S . D .=$ standard deviation. See text for more detail

\begin{tabular}{|c|c|c|c|c|c|c|c|c|}
\hline \multirow[b]{2}{*}{ Sample } & \multirow{2}{*}{$\begin{array}{c}\text { Initial- } \\
\text { final } \\
\text { year }\end{array}$} & \multirow[b]{2}{*}{$n$} & \multicolumn{2}{|c|}{$a_{1}$ estimate } & \multicolumn{2}{|c|}{ Initial SVL } & \multicolumn{2}{|c|}{ Final SVL } \\
\hline & & & Mean & S.D. & Mean & $(\min ., \max )$. & Mean & $(\min ., \max )$. \\
\hline 1985 cohort & $1985-1986$ & 67 & $2 \cdot 609$ & $0 \cdot 355$ & $18 \cdot 0$ & $(16 \cdot 2,19 \cdot 6)$ & $27 \cdot 6$ & $(21 \cdot 5,35 \cdot 6)$ \\
\hline 1985 cohort & $1986-1987$ & 23 & $2 \cdot 380$ & 0.534 & $27 \cdot 2$ & $(22 \cdot 4,32 \cdot 0)$ & $32 \cdot 5$ & $(27 \cdot 8,35 \cdot 5)$ \\
\hline 1985 cohort & $1987-1988$ & 6 & 5.085 & $2 \cdot 033$ & $31 \cdot 9$ & $(30 \cdot 0,33 \cdot 8)$ & 34.9 & $(33 \cdot 3,36 \cdot 6)$ \\
\hline Population & $1986-1987$ & 143 & $2 \cdot 501$ & 0.832 & $26 \cdot 4$ & $(17 \cdot 5,41 \cdot 2)$ & $31 \cdot 3$ & $(21 \cdot 8,45 \cdot 2)$ \\
\hline Population & $1987-1988$ & 85 & 3.675 & $1 \cdot 280$ & $27 \cdot 6$ & $(16.9,47.9)$ & $31 \cdot 8$ & $(22 \cdot 3,51 \cdot 5)$ \\
\hline 1985 cohort & $1985-1987$ & 41 & $2 \cdot 484$ & $0 \cdot 241$ & 17.9 & $(16 \cdot 2,19 \cdot 5)$ & $32 \cdot 6$ & $(27 \cdot 8,36 \cdot 4)$ \\
\hline 1985 cohort & $1985-1988$ & 11 & $2 \cdot 918$ & $0-269$ & $18 \cdot 1$ & $(16.7,18.9)$ & $34 \cdot 8$ & $(30 \cdot 5,37 \cdot 4)$ \\
\hline 1985 cohort & $1986-1988$ & 7 & 3.557 & 0.494 & $29 \cdot 1$ & $(28 \cdot 1,31 \cdot 0)$ & $34 \cdot 6$ & $(30 \cdot 5,37 \cdot 4)$ \\
\hline Population (SVL $<30$ ) & $1987-1988$ & 60 & $3 \cdot 291$ & 0.856 & $24 \cdot 9$ & $(16 \cdot 9,29 \cdot 8)$ & $29 \cdot 6$ & $(22 \cdot 3,35 \cdot 2)$ \\
\hline Population (SVL > 30) & $1987-1988$ & 25 & $4 \cdot 597$ & 1.6149 & $33 \cdot 8$ & $(30 \cdot 0,47 \cdot 9)$ & $37 \cdot 2$ & $(32 \cdot 5,51 \cdot 5)$ \\
\hline
\end{tabular}

the samples and the age of the snakes. For example, for the population samples made during 19861987 and 1987-1988, the mean estimates of the slope of the scaling relation were 2.50 and 3.68 , respectively, and the difference between these values was highly significant $(t=7.56, P<0.001)$, indicating that snakes gained more mass per unit length in 1987-1988 than in 1986-1987. Even 
within a single time period, there was significant variation in slope attributable to the size of the snakes. When the 1987-1988 sample was divided into a small (1987 SVL $<30 \mathrm{~cm}$, smaller than cohort snakes) and a large (1987 SVL $>30 \mathrm{~cm}$ ) group, the difference between the respective mean estimates of slope, 3.29 and 4.60 , was highly significant $(t=3.82, P<0.001)$.

To avoid possible confounding effects of pooling data from snakes of many different ages, the longitudinal allometries are given for the 1985 cohort as well as the population samples (Table II). For the first (1985-1986) and second (1986-1987) years in the lives of the 1985 cohort snakes, the difference between the mean estimated slopes of 2.61 and 2.38 was not significant $(t=1.92$, $P=0.07)$. The difference between the mean estimates of slopes from the second (1986-1987) and third years $(1987-1988)$ (slope $=5.09)$ in the lives of the 1985 cohort snakes was significant $(t=2.98, P=0.02)$, with relatively more mass being gained per unit length in the third year. When the longitudinal estimate of slope of the mass-SVL scaling relationship was calculated for the 1985 cohort over the entire length of the study (2.918, Table II), it was nearly identical to that calculated using cross-sectional allometry $(2 \cdot 928$, Table I).

\section{Cross-sectional allometry of burst speed}

As shown in Fig. 2, $\log$ (burst speed) increases significantly with $\log$ (snake size), but not with a simple linear relationship. Instead, there is a highly significant quadratic effect of log size on log burst speed with maximal slope of the relationship (about 1.6) occurring at the smallest SVL. Table I summarizes the regression equations for $\log$ (burst speed), measured over 25, 50, 75 and 100 $\mathrm{cm}$ intervals ( $V 25, V 50, V 75$ and $V 100)$, as a second degree polynomial of $\log (\mathrm{SVL})$. Although a maximal speed is predicted for snakes approximately $50 \mathrm{~cm}$ SVL, the predicted burst speed for snakes with SVL $>40 \mathrm{~cm}$ is nearly constant. For smaller snakes (SVL $<35 \mathrm{~cm}$ ), scaling of burst speed is adequately modelled by simple first degree log-log regression of SVL with a slope of about

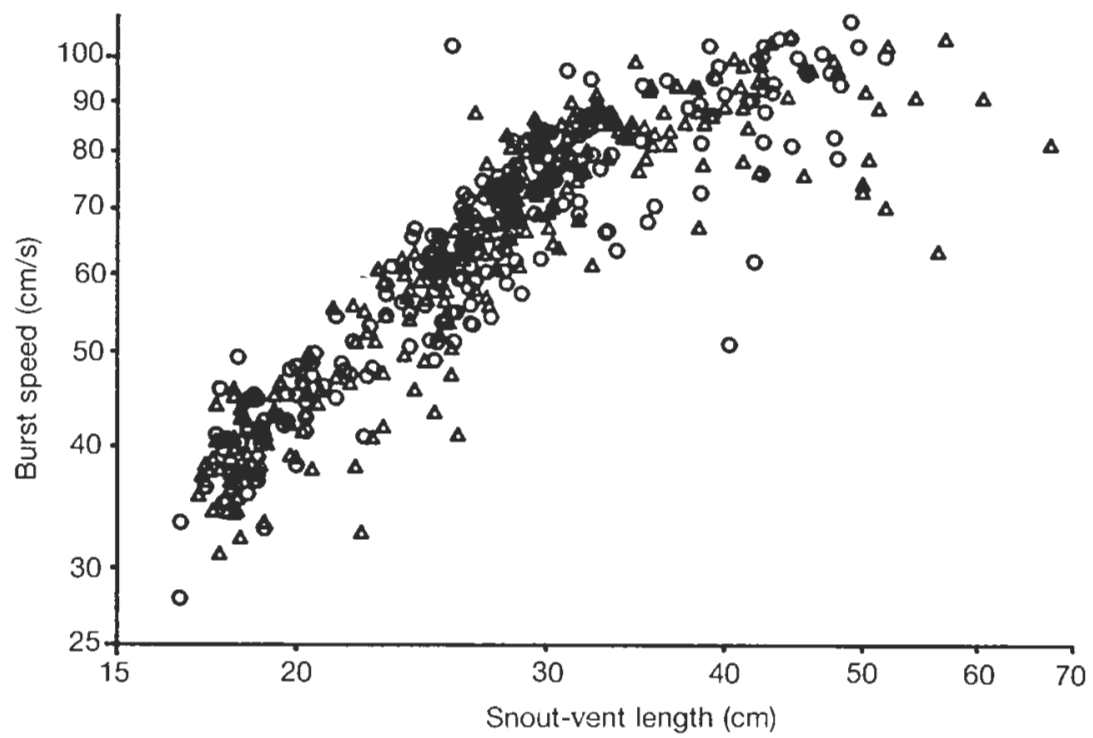

FIG. 2. Burst speed (V50) versus snout-vent length (SVL) for 497 snakes tested during 1986. Note that both the $x$ and $y$ axes use a log scale. $O$, males; $\Delta$, females. 
TABLE III

Summary of percentage variance components (10 nearest 1\%) for each of four nested ANOVAs performed on burst speed residuals. Intervallength indicates the distance over which burst speed was measured. ns indicates not significant $(P>0.05)$ and ** indicates $P<0.001$. The ranges of $S V L(\mathrm{~cm})$ of the six snakes

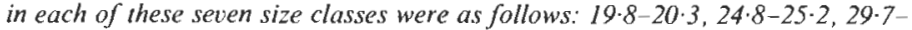
$30 \cdot 2,34 \cdot 5-35 \cdot 7,39 \cdot 3-41 \cdot 2,44 \cdot 5-46 \cdot 0$ and $48 \cdot 0-50 \cdot 5$. See text for more detail

\begin{tabular}{|c|c|c|c|c|}
\hline \multirow[b]{2}{*}{ Variance component } & \multicolumn{4}{|c|}{ Interval length $(\%)$} \\
\hline & $25 \mathrm{~cm}$ & $50 \mathrm{~cm}$ & $75 \mathrm{~cm}$ & $100 \mathrm{~cm}$ \\
\hline Size class $(n=7)$ & $0 \mathrm{~ns}$ & $0 \mathrm{~ns}$ & $4 \mathrm{~ns}$ & $2 \mathrm{~ns}$ \\
\hline Individual ( 6 individuals/size class) & $38 * *$ & $65 * *$ & $68 * *$ & $75 * *$ \\
\hline Error (4 trials/individual) & 62 & 35 & 28 & 23 \\
\hline
\end{tabular}

4/3. Entering a variable for sex into the multiple regression predicting speed from SVL revealed no significant effect of $\operatorname{sex}(P=0.40)$.

Burst speed predicted for a given SVL decreased about $20 \%$ as the interval used to measure it increased from 25 to $100 \mathrm{~cm}$. To quantify the effect of interval length on the variance of burst speed residuals, nested analyses of variance (Sokal \& Rohlf, 1981) were performed separately on $V 25$, $V 50, V 75$ and $V 100$ residuals from a subsample of 42 snakes tested during 1986. Six individuals were included for each of seven levels of a size factor which was used as a blocking variable. Nested within each individual were values of burst speed residuals from each of the four trials performed per snake. As shown in Table III, the variance among individuals was always a highly significant source of variation, and the percentage error component decreased with increased interval length. We chose to emphasize analysis of burst speed measured over $50 \mathrm{~cm}$ as this was the shortest interval with an acceptable error component.

For studies of limbless locomotion, it has been common to convert speed to total lengths per second, and physiologically oriented studies often have been interested in scaling relationships with mass. Consequently, the regression equations for $\log (V 50)$ as a function of $\log (\mathrm{TL})$ and $\log$ (mass) are included in Table I. As indicated by a comparison of the $r^{2}$ values of the regressions predicting V50, using SVL gave a slightly better description of the scaling relationship than either TL or mass alone. Using SVL as a measure of size also avoided some of the difficulties associated with sexual dimorphism and partial tail loss; therefore, SVL was chosen as the primary indicator of size to be used for additional analyses.

The mass residual calculated from the regression using SVL of males and females combined (Table I, $n=497$ ) indicates the relative heaviness of a snake for a given SVL, and this quantity might be expected to affect locomotor performance. As will be discussed in more detail later, there was a significant negative correlation $(r=-0.105, P=0.02)$ between $V 50$ residual (predicted from the second degree polynomial of $\log (S V L)$ ) and (mass residual) ${ }^{2}$. However, there was no significant correlation $(r=0.056, P=0.22)$ between $V 50$ residuals and a simple first degree term of mass residuals.

\section{Cross-sectional allometry of endurance}

Figure 3 illustrates that endurance time (ET) increased significantly with size. Unlike burst speed, $\log ($ endurance) was adequately modelled as a linear relation of $\log ($ size $)$. Table I lists the 


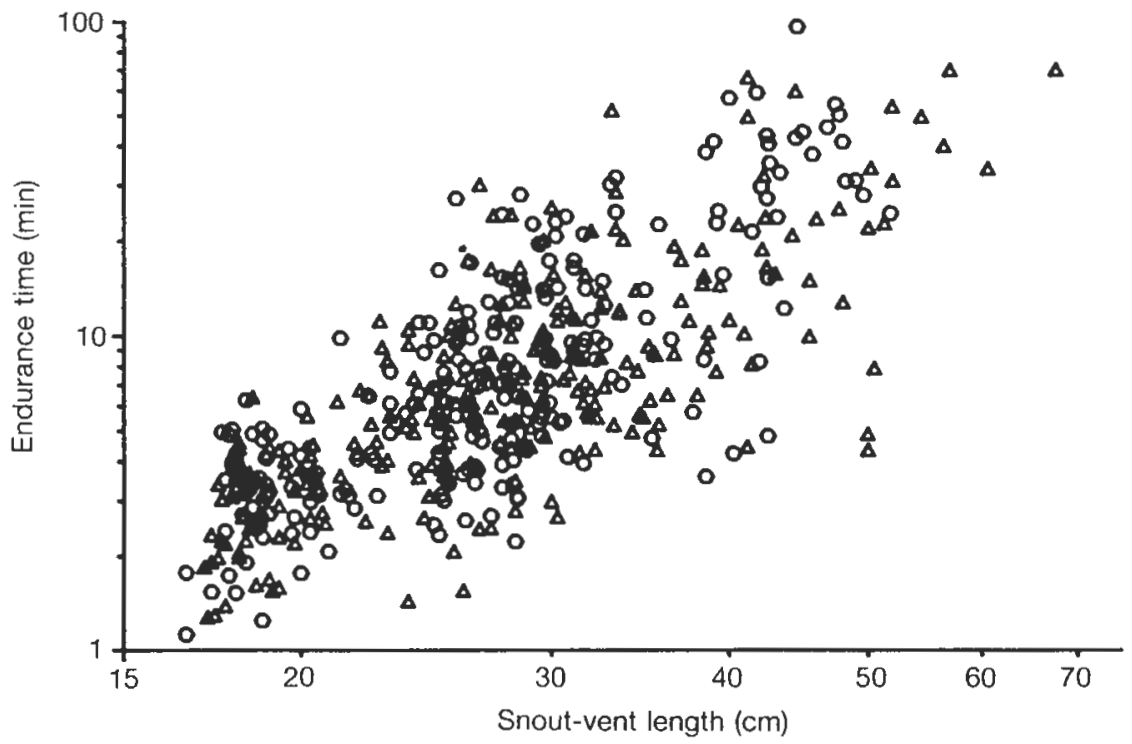

FIG. 3. Endurance time (ET) versus snout-vent length (SVL) for the 497 snakes tested during 1986. Note that both the $x$ and $y$ axes use a log scale. $O$, males; $\Delta$, females.

scaling regressions for $\log (\mathrm{ET})$ as a function of $\log (\mathrm{SVL}), \log (\mathrm{TL})$ and $\log$ (mass). The slope of the scaling equation was about $2 \cdot 3$ for the entire size range of snakes and for a sample restricted to snakes with $S V L<35 \mathrm{~cm}$. Over the entire size range of the 497 snakes, females had less endurance time than males of equal SVL, as shown by a multiple regression which had a highly significant $(P=0.006)$ but weak effect of sex $(1=$ male, $2=$ female $)$ on ET, $(\log (\mathrm{ET})=-2.357+2.292$ $\log (\mathrm{SVL})-0.060 \mathrm{sex}, r^{2}=0.579$ versus 0.573 for pooled sample). For the snakes with $\mathrm{SVL}<35 \mathrm{~cm}$, a similar multiple regression analysis, using $\log (\mathrm{SVL})$ and sex as the independent variables, revealed no significant effect of sex on ET. Assuming the overall direction the snakes crawled was a straight line, one can estimate the endurance distance (ED) in metres (Table I). The endurance of snakes increases dramatically with size as indicated by the anti-log of the values the regressions predicted for a small $(\mathrm{SVL}=20 \mathrm{~cm}, \mathrm{ET}=3.4 \mathrm{~min}, \mathrm{ED}=28 \mathrm{~m})$, medium $(\mathrm{SVL}=35 \mathrm{~cm}, \mathrm{ET}=12$ $\min , \mathrm{ED}=102 \mathrm{~m})$ and large snake $(\mathrm{SVL}=50 \mathrm{~cm}, \mathrm{ET}=28 \mathrm{~min}, \mathrm{ED}=231 \mathrm{~m})$.

The differential effect of sex on snakes of different size and the sexual dimorphism in mass suggested that a variable relating mass to SVL could have significant predictive value for endurance or that there might be a significant interaction between size and sex on endurance. To explore these possibilities, additional multiple regressions were calculated. The mass residual calculated from the SVL (Table $\mathrm{I}, n=497$ ) indicates the relative heaviness of a snake, and multiplying sex by $\log (\mathrm{SVL})$ yields an interaction term between sex and size. For all 497 snakes, the relative heaviness of snakes had a highly significant $(P=0.0004)$ negative effect on endurance $\left(\log (\mathrm{ET})=2.439+2.284 \log (\mathrm{SVL})-0.698\right.$ (mass res.), $\left.r^{2}=0.584\right)$. The interaction term of sex times $\log (\mathrm{SVL})$ had a marginally significant $(P=0.04)$ negative effect on endurance time when it was entered into a multiple regression including $\log (\mathrm{SVL})$ and mass residual as independent variables. 


\section{Correlation of size-corrected speed and endurance}

Figure 4 shows the low but highly significant positive correlation $(r=0.263, P<0.001)$ between the $V 50$ and ET residuals calculated from SVL of the 497 snakes tested during 1986. As indicated by the value of $r^{2}$, a regression predicting $V 50$ from ET residual would account for only about $5 \cdot 6 \%$ of the total variance in $V 50$ residual. Figure 4 shows a preponderance of points with negative values for both variables that probably contributed to this significant relationship between speed and endurance residuals. When correlation coefficients of V50 and ET residual were calculated separately for a divided data set in which one sample had ET residuals less than the median and another sample had ET residuals greater than or equal to the median, the sample with ET residual less than the median had a highly significant positive correlation $(r=0.400, n=250, P<0.001)$ and the other sample had no significant correlation $(r=0 \cdot 109, n=247, P=0.089)$. In other words, if snakes have low endurance, they are likely to have poor speed, but it is not likely that snakes will have both good speed and good endurance. Similar results were found when the correlations between speed (V50) and endurance (ET) residuals were also calculated for the tests made during the other three years of the study $(1985,1987$ and 1988).

\section{Longitudinal allometry of speed}

Longitudinal estimates of the scaling of performance with size, shown in Table IV, gave highly variable results depending on the sample. The change in log speed with change in log size varied from about -3.7 to 1.6 when SVL was used and from about -0.8 to 0.6 when mass was used to indicate size. To test for the effects of snake size on the longitudinal estimates of the scaling of speed, means were calculated and compared for subsamples of some of the larger samples. The

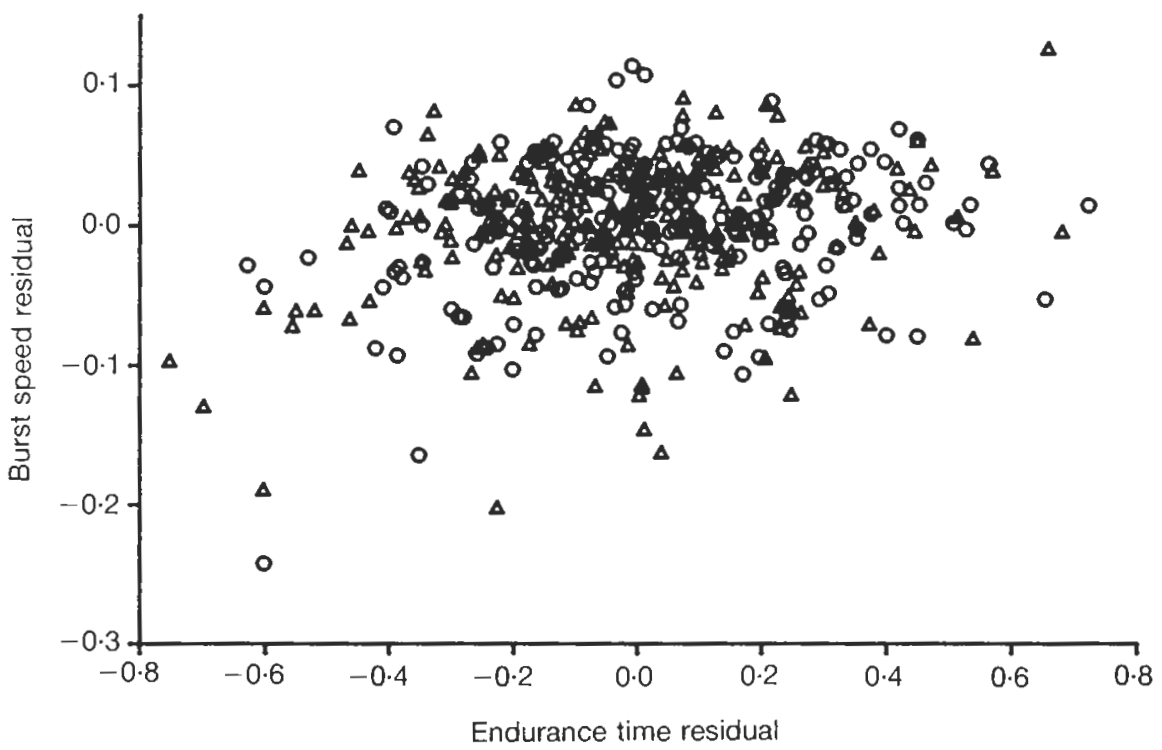

FIG. 4. Size-corrected burst speed ( $/ 50$ residual) versus size-corrected endurance (ET) for each of the 497 snakes tested during 1986. 0 , males; $\Delta$, females. 
greatest estimated slopes were for the smallest snakes (cohort 1985-1986, Table IV), regardless of whether SVL or mass was used as the measure of size. Comparing measurements made on the 1985 cohort from 1985-1986 to those from 1986-1987 revealed significant differences both for the slope of speed with SVL $(t=4.90, P<0.001)$ and for the slope of speed with mass $(t=3.44, P<0.001)$. Similarly, subdividing some samples from the same time interval into small and large snakes revealed different scaling of speed with size. For example from 1986-1987, the slope of change in speed with SVL of 36 neonates $(1986 \mathrm{SVL}<23 \mathrm{~cm})$ versus that of 102 subadults $(23 \mathrm{~cm}<\mathrm{SVL}<35$ $\mathrm{cm})$ was significantly grcater $(1.505$ vs. $0.582, t=5.89, P<0.001)$.

To determine the relation between snake size and the change in $\log (V 50)$ with $\log (\mathrm{SVL})$ for these 1986-1987 data, we calculated a regression with slope as the dependent variable, $Y$, and the a verage of 1986 and $1987 \log (\mathrm{SVL})$ of each of 143 snakes as the independent variable, $X$. There was a highly significant negative relation between these two quantities $\left(r^{2}=0.168, P<0.0001\right)$ with the regression equation being $Y=12 \cdot 641-8 \cdot 159 \mathrm{X}$. This regression indicates that the mean of the longitudinal estimates of the slope of change in log speed with change in log SVL did not adequately describe the scaling relationship, but rather that the slope of the scaling relationship is a function of the size of the snake. Substituting a few values into this equation indicates that the slope of a log-log plot of V50 versus SVL is high for small snakes $(2.0393$ when SVL $=20 \mathrm{~cm})$, positive but smaller for larger snakes $(0.59$ when $S V L=30 \mathrm{~cm})$ and negative for large snakes $(-0.43$ when $S V L=40 \mathrm{~cm})$.

TABLE IV

Longitudinal estimates (mean) of $a_{l}$, the slope of the scaling equation log (performance) $=a_{1}{ }^{*} \log$ ( size), where size is either SVL or mass. Initial and final refer to the first and second points in time for which measurements were made. $n=$ somple size, S.D. = standard deviation. For the slope of speed, initial and finat size ranges are identical to those given in Table 11 , and for endurance. the size ranges are similar. See text for more detail

\begin{tabular}{|c|c|c|c|c|c|c|}
\hline \multirow[b]{2}{*}{ Sample } & \multirow{2}{*}{$\begin{array}{c}\text { Initial- } \\
\text { final } \\
\text { year }\end{array}$} & \multirow[b]{2}{*}{$n$} & \multicolumn{2}{|c|}{$\begin{array}{l}a_{1} \text {, slope } \\
\text { wilh SVL }\end{array}$} & \multicolumn{2}{|c|}{$\begin{array}{l}a_{1}, \text { slope } \\
\text { with mass }\end{array}$} \\
\hline & & & Mean & S.D. & Mean & S.D. \\
\hline \multicolumn{7}{|l|}{ Speed (V50) } \\
\hline 1985 cohort & $1985-1986$ & 67 & 1.622 & 0.393 & 0.644 & 0.257 \\
\hline 1985 cohort & $1986-1987$ & 23 & 0.952 & 0.614 & 0.416 & $0 \cdot 321$ \\
\hline 1985 cohort & $1987-1988$ & 6 & $-3 \cdot 702$ & $2 \cdot 215$ & -0.814 & 0.415 \\
\hline Population & $1986-1987$ & 143 & 0.781 & $\mathrm{I} \cdot 10 \mathrm{I}$ & 0.393 & 0.827 \\
\hline Population & 1987-1988 & 85 & $-1 \cdot 500$ & 1.710 & -0.455 & $0 \cdot 524$ \\
\hline 1985 cohort & $1985-1987$ & 41 & 1.336 & $0 \cdot 24 l$ & 0.543 & $0 \cdot 117$ \\
\hline 1985 cohort & $1985-1988$ & II & 0.832 & $0 \cdot 285$ & 0.289 & $0 \cdot 109$ \\
\hline 1985 cohort & $1986-1988$ & 7 & -1.372 & {$[\cdot 74 !$} & $-0 \cdot 350$ & $0 \cdot 398$ \\
\hline \multicolumn{7}{|c|}{ Endurance (ET) } \\
\hline 1985 cohort & $1986-1987$ & 23 & 0.593 & $2 \cdot 885$ & 0.295 & 1.303 \\
\hline 1985 cohort & I987-1988 & 5 & $2 \cdot 296$ & $6 \cdot 249$ & $1 \cdot 117$ & 1.912 \\
\hline Population & $1986-1987$ & 127 & 0.544 & $5 \cdot 239$ & $0 \cdot 132$ & 3.071 \\
\hline Population & $1987-1988$ & 34 & $3 \cdot 172$ & $5 \cdot 645$ & 0.957 & $1.42 I$ \\
\hline 1985 cohort & $1986-1988$ & 7 & $-2 \cdot 254$ & $5 \cdot 165$ & -0.539 & $1 \cdot 313$ \\
\hline
\end{tabular}




\section{Longitudinal allometry of endurance}

Table IV summarizes the longitudinal estimates of the scaling of endurance with size. Because the snakes were tested at a different tread speed in 1985 than in other years, these measurements were not used for this part of the analysis. Mean estimates of change in log(endurance) with change in $\log$ (size) varied from -2.3 to 2.3 when SVL was used and from -0.5 to 1.1 when mass was used for size. Without exception the standard deviations of the longitudinal estimates of the scaling of endurance were greater than those for the longitudinal estimates of the scaling of speed calculated over the same time interval. As one might expect from the relatively large error associated with the longitudinal estimates of the scaling of endurance, no significant differences were found comparing samples either from different time intervals or of different size ranges of snakes. For all 127 snakes in the 1986-1987 sample, change in $\log$ (endurance) showed no significant correlation $(r=0.01, P=0.88)$ with the mean of initial and final $\log (\mathrm{SVL})$, indicating that longitudinal estimates of the slope of the scaling relationship can be compared directly to the slope of the crosssectional scaling regressions (Table I). Interestingly, endurance increased with size from 1987 to 1988 whereas size-corrected speed decreased during this time interval, as discussed earlier.

\section{Repeatability of size-corrected measures}

The repeatability of measurements refers to the error of the measurement relative to the genuine variation occurring among different individuals. One method for determining this quantity is to calculate the correlation between pairs of size-corrected measurements taken at two different times for all of the individuals in a sample. Table $\mathrm{V}$ summarizes the repeatabilities of speed (V50), endurance (ET), and mass residuals for different time periods. The testing protocol allowed calculations of repeatability between successive days ( $V 50$ residuals from day 1 and day 2 and ET

\section{TABLE V}

Correlation coefficients (Pearson's $r$ ) indicating repearability of size-corrected measurements between pairs of measurements made at differenl limes. Repealabilities are listed for burst speed (V50). endurance time and mass residuals. Afler each correlation coefficient, sample size and $\boldsymbol{P}$ values are indicated in parentheses. Note values along the two main diagonals of performance measures indicate the day-to-day repeatabilities

\begin{tabular}{|c|c|c|c|c|}
\hline & 1985 & 1986 & 1987 & 1988 \\
\hline \multicolumn{5}{|l|}{ Speed } \\
\hline 1985 & $0.775(271,<0.001)$ & $0.646(67 .<0 \cdot 001)$ & $0.178(41,0.265)$ & $-0.523(11,0.098)$ \\
\hline 1986 & - & $0.656(497,<0.001)$ & $0.253(185,0.001)$ & $-0 \cdot 121(51,0 \cdot 397)$ \\
\hline 1987 & - & - & $0.798(483,<0.001)$ & $0.059(102,0.559)$ \\
\hline 1988 & - & - & - & $0.624(284,<0.001)$ \\
\hline \multicolumn{5}{|c|}{ Endurance } \\
\hline 1985 & $0.672(274,<0.001)$ & $0 \cdot 250(67,0 \cdot 041)$ & $0.174(41,0.277)$ & $0.270(10,0.450)$ \\
\hline 1986 & - & $0.567(497,<0.001)$ & $0.217(166,0.005)$ & $0.235(50,0 \cdot 101)$ \\
\hline 1987 & - & - & $0.616(206,<0.001)$ & $0 \cdot 434(40,0 \cdot 005)$ \\
\hline 1988 & - & - & - & $0.508(57,<0.001)$ \\
\hline \multicolumn{5}{|c|}{ Mass residual } \\
\hline 1985 & - & $0.370(67,0.002)$ & $0.324(41,0.039)$ & $0.064(11,0.851)$ \\
\hline 1986 & - & - & $0.469(185,<0.001)$ & $0.151(51,0.291)$ \\
\hline 1987 & - & - & - & $0 \cdot 148(102,0 \cdot 138)$ \\
\hline
\end{tabular}


residuals from days 3 and 4 ) and between various years in which individuals were recaptured and retested.

The day-to-day repeatabilities of burst speed ranged from 0.624 to 0.775 during the four years of the study, and these correlations were all highly significant (Table V). During 1987, 86 snakes were captured and retested from three to eight weeks after the initial tests of burst speed, and the correlation between $V 50$ residuals from these two times was also highly significant $(r=0 \cdot 341$, $P=0.001$ ). Not surprisingly, longer time intervals between pairs of tests on individuals decreased repeatability (Table V). However, the measurements of burst speed still had highly significant repeatability one year later in both the 1985-1986 and 1986-1987 comparisons (Table V).

The repeatability of end urance measures showed similar trends to those of burst speed. The dayto-day repeatabilities ranged from 0.508 to 0.672 during the four different years, and all of these correlations were highly significant (Table V). Measures of endurance also were significantly repeatable across successive years, although these values were always lower than the day-to-day repeatabilities (Table V). Pair-wise comparisons of the repeatabilities of speed and endurance over the same time intervals show that endurance usually had a lower repeatability than burst speed (Table V).

Table $\mathrm{V}$ also lists the repeatabilities of the mass residuals between different years. For two of the one-year intervals between measurements (1985-1986, 1986-1987), this quantity had a highly significant repeatability (Table V). For the 86 snakes with more than three weeks between captures in 1987 , there was also significant repeatability of the mass residual data. Keeping in mind that most of these snakes were still not of reproductive size, this result suggests that a snake that is relatively heavy at one point in time will probably be heavy at a later point in time.

\section{Heritability of size-corrected measures}

Heritability refers to the extent to which genetic factors contribute to the variance of an observed trait. Assuming the snakes within a litter are full sibs, the maximum value of the heritability of a trait may be estimated as twice the value of the component of variance attributable to litters. For the 1985 cohort there were 264 snakes from 34 litters with two or more individuals each of which had no missing values for any of the performance trials. Using a single mean value for each of these 264 snakes, we performed a one-way ANOVA and found the percentage variance components attributable to litter for $V 50$, endurance time and mass residuals were $14 \%$, $34 \%$ and $36 \%$, respectively, and all of these variance components were very highly significant $(P<0.0001)$, yielding respective heritabilities of $0.28,0.68$ and 0.72 . Performing separate one-way ANOVAs for the values from each performance trial gave results similar to those for mean performance values.

The methods outlined above are those conventionally used to calculate heritability, but it is also instructive to utilize the replication of performance tests (four trials for $V 50$ and two for ET) to estimate the relative size of the variance component due to litter compared to the variance among individuals within litter and the variance among trials within an individual. For the nested ANOVA on the residual burst speed scores, the variance components attributable to litter, individuals nested within litter, and trials nested within individual were 10\%, 57\% and 33\%, respectively. These same respective variance components for endurance residual values were $16 \%$, $46 \%$ and $38 \%$. For both burst speed and endurance, among-litter variance was highly significant, but it is also interesting to note the relatively large (and highly significant) amount of variance occurring among different individuals within a litter. 
During 1986, 61 neonates from 10 field-fresh females were tested within two days of birth allowing a separate calculation of variance attributable to litter. Performing a one-way ANOVA on mean values of $V 50$, endurance and mass residuals revealed the variance components due to litter effects were $55 \%, 39 \%$ and $47 \%$, respectively, and all of these components were highly significant. A second set of measurements was made on these individuals six weeks after the initial test, and another one-way ANOVA was performed on the measurements. For these second measures of $V 50$, endurance and mass residuals, the variance components attributable to litter were $20 \%(P=0.019), 1 \%(P=0.39)$ and $40 \%(P<0.0001)$, respectively. As indicated by the probabilities of significant litter effects, size-corrected endurance was not significantly heritable six weeks after birth, but speed and mass variables were still significant. Despite the decreased significance of litter effects for the second compared to first test, the repeatability of all sizecorrected measures between the first and second measurements was highly significant, as indicated by correlation coefficients between the first and second measures of $V 50$, endurance and mass residuals of $0 \cdot 47,0.40$ and $0 \cdot 47$, respectively.

\section{Effects of pregnancy on performance}

To determine the effects of pregnancy on locomotor performance, comparisons were made among three groups of snakes (males, $n=8$; non-gravid females, $n=16$; and gravid females, $n=15$ ) with an SVL greater than or equal to that of the smallest gravid female $(46 \mathrm{~cm})$ that was tested during 1986. Figure 5 illustrates the mean locomotor performance of these groups using both absolute and size-corrected values. A Mann-Whitney $U$-test was used to test for significant differences among pairs of groups. Gravid females had significantly slower burst speed (V50) and less endurance than other similarly-sized snakes. The mean burst speed of gravid snakes $(74.0 \mathrm{~cm} / \mathrm{s})$ was significantly less than that of both large non-gravid females $(88.6 \mathrm{~cm} / \mathrm{s})$ and large males $(95.6$ $\mathrm{cm} / \mathrm{s}$ ), but there was no significant difference between large males and large non-gravid females. The size-corrected values of $V 50$ had a pattern of differences among groups that was identical to that of the values of $V 50$. The only significant differences in mean endurance time occurred

Speed

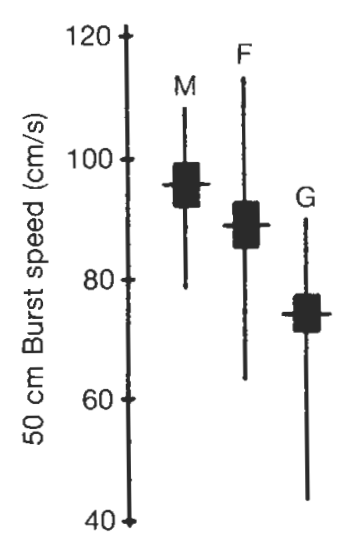

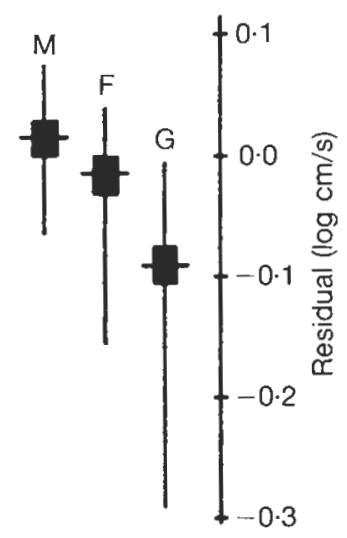

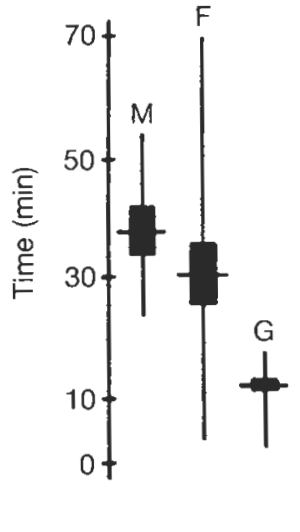

Endurance

FIG. 5. Mean (horizontal line), standard deviation (thick vertical line) and range (thin vertical line) for large snakes (SVL $\geq 46 \mathrm{~cm}$ ). M, F and G indicate male, non-gravid female and gravid female, with sample sizes of 8,16 and 15 , respectively. 
between gravid females ( $7.6 \mathrm{~min})$ and both non-gravid females $(31.6 \mathrm{~min})$ and males $(38.3 \mathrm{~min})$. The mean endurance time residual (calculated from pooled data in Table I) of gravid females $(-0.0961)$ was significantly less than both that of non-gravid females $(-0.0223)$ and males $(0 \cdot 0107)$. Large non-gravid females also had significantly lower endurance time residuals than large males.

\section{Discussion}

\section{Effects of size}

As indicated by the scaling relations described in this study, snakes undergo significant changes in shape and locomotor capacity as they grow. We found 10 -fold increases in endurance capacity and a doubling of burst speed comparing neonates to large adults. As emphasized by Pough (1978) in his study of endurance in water snakes, the different physiological capacities of small, young reptiles and adults may have profound ecological consequences and young reptiles should not be considered merely small replicates of adults.

It seems likely that increases in absolute speed with increased size could have important ecological consequences. For example, the time taken to crawl to a safe retreat is dependent on the absolute speed $(\mathrm{cm} / \mathrm{s})$ not the relative speed $(\mathrm{TL} / \mathrm{s})$; therefore, larger snakes may have an advantage when a predator is encountered. Other observations on this population suggest that survivorship is directly related to size-corrected burst speed in snakes over one year of age (B. C. Jayne \& A. F. Bennett, unpubl. data). Unfortunately, so little is known about the ecology of snakes that it is not clear exactly what advantages increased speed may confer, but this lack of information suggests a topic for future research that may prove very productive. An example of how size-dependent locomotor performance may be correlated to ecology is provided by Huey \& Hertz (1984), who related the size of lizards to their ability to accelerate. Using acceleration and maximal speeds, they predicted that under certain conditions a larger lizard would not be able to accelerate quickly enough to catch a small lizard over a limited distance.

Our study found that above a certain SV-length (approximately $50 \mathrm{~cm}$ ), speed no longer increases with size (Fig. 2), and this is similar to Heckrotte's (1967) observation that the fastest speeds were not attained by the longest snakes. Gans (1974) suggested that this decreased performance for the larger snakes resulted from the spacing of pivotal points being too close to allow the largest snakes to obtain maximal speed, and spacing of pivotal points is known to affect the speed of snakes (Bennet, McConnell \& Trubatch, 1974; Jayne, 1986). Although preliminary performance trials with different substrata such as pegs indicated that the fastest speeds were attained by snakes crawling on artificial turf, the substratum used in the present study indeed may have differentially slowed the largest snakes. However, in a given ecological setting (such as the site of capture in this study), snakes of all sizes commonly crawl on an identical substratum. Hence, potentially differential effects of substratum on locomotor performance of snakes of different sizes is another interesting way in which size may constrain locomotor performance in a natural setting.

In contrast to burst speed (Fig. 2), this study found that endurance capacity increased over the entire size range of animals (Fig. 3), implying that changes in speed and endurance are not necessarily coupled to each other during the entire ontogeny of an individual. Furthermore, comparing the endurance of male and female snakes revealed that females had less endurance than males of equal length, perhaps associated with the observation that medium-to large-sized females were more massive than males. 
One would expect that increases in mass not attributable to larger size of the locomotor apparatus should detrimentally affect locomotor performance, and accumulation of fat, gastrointestinal contents and developing young are three such sources of increased mass. The increase in the mass of abdominal fat bodies as snakes mature has been well documented (Seigel \& Ford, 1987). Hence, it is likely that the greater mass of large females results partially from a disproportionate increase in fat that has a detectable, detrimental effect on endurance. Other studies have found significant negative effects of mass of stomach contents on maximal speed and endurance (Garland \& Arnold, 1983; Ford \& Shuttlesworth, 1986). This study found that gravid snakes had significantly lower speed and endurance than non-gravid snakes of similar length. The recent study of Seigel, Huggins \& Ford (1987) suggests that depressed locomotor performance of gravid snakes may not be attributable solely to the overall increased mass of the female. Seigel et al. (1987) tested locomotor performance in gravid garter snakes at different stages during the course of pregnancy and two to three weeks after parturition; they found a significant effect of stage on performance, and the mean post-parturition performance was lower than that of some of the stages during pregnancy. Consequently, the detrimental effect of pregnancy on performance may involve changes in physiology, behaviour or declining health of the individuals rather than just the mechanical effects of added mass.

The mass of an individual relative to some function of a linear measurement has been used as an indicator of the relative health ('condition') of individuals within a population (e.g. Van Berkum et al., 1989), and in this study the mass residuals predicted from SVL may also provide some indication of overall condition. If animals are emaciated (negative mass residual) one might expect that they would have depressed locomotor performance, but, as shown above, relatively fat individuals (positive mass residual) would also be expected to have poor performance. Hence, it is likely the individuals deviating strongly from the mean mass residual in either a negative or a positive direction might have decreased performance. As shown in Arnold \& Bennett (1988), finding a negative correlation between performance and a squared term of a variable suggests such a case. For the 497 snakes captured and tested during 1986, there was a significant negative correlation between square of mass residual and both the (V50) speed residual $(r=-0 \cdot 105$, $P=0.020)$ and the endurance residual $(r=-0.244, P<0.001)$. Although it seems likely that increasing energy stores during growth could be an advantage for the reproduction and survival of Thamnophis sirtalis, these negative correlations suggest a small cost in locomotor performance also is associated with such growth.

\section{Comparison of cross-sectional and longitudinal allometries}

Overall, generally similar results were obtained by using cross-sectional and longitudinal sampling. For burst speed, analysis of the results was complicated somewhat by the non-linear change of $\log$ (speed) with $\log ($ size). However, both the cross-sectional and longitudinal methods detected this non-linear scaling relation. Similarly, both sampling methods indicated that the log$\log$ relation of endurance to length was adequately modelled with a constant slope.

Ranking the dependent variables of the cross-sectional scaling regressions using the values of $r^{2}$ (Table I) reveals that scaling relations account for the greatest proportion of variance in mass and the least proportion of variance in endurance with burst speed being intermediate. Similarly, comparing the ratio of standard deviation to the mean estimate of slope for the longitudinal scaling data from the same sample periods (Tables II \& IV) ranked the dependent variables in the order mass, burst speed and endurance from best to worst longitudinal estimate. The ranking of 
these three variables in order of the accuracy of the scaling relations is congruent with ranking based on repeatability, suggesting that differences in measurement error of the dependent variable are largely responsible for different errors in estimating the scaling relationships. Perhaps ontogenetic trajectories of morphology also are generally more predictable than those of performance because performance involves the complex combination of morphology, behaviour and function.

In contrast to the cross-sectional sample, the longitudinal samples were able to detect some significant differences in change in mass with length that were attributable to the year of the study and to snakes of different age classes (Table II). Longitudinal studies are therefore more likely to provide insight for ecologically oriented studies. Perhaps, for instance, annual variation in growth rate in this study might have resulted from different prey densities or different thermal conditions. Tests of significance between cross-sectional and longitudinal estimates are complicated by the different standard errors associated with the estimates of the slope of the scaling relationships. The slopes of the scaling relation between mass and SVL for cross-sectional and longitudinal (from 1986 to 1987 ) samples were 2.93 and $2 \cdot 50$, respectively.

For the cross-sectional sample (Table I), the slope of the scaling of speed with SVL was 1.59 when $S V L=20 \mathrm{~cm}$ and 0.90 when $S V L=30 \mathrm{~cm}$. Using the regression of scaling of change in speed with SVL for the 1986-1987 longitudinal data predicted a slope of 2.04 when $S V L=20 \mathrm{~cm}$ and 0.59 when $\mathrm{SVL}=30 \mathrm{~cm}$. For a longitudinal sample of small snakes (1985 cohort from 1985 to 1986) speed changed with SVL raised to the 1.62 power. Hence, for snakes of similar size, it was common for the cross-sectional and longitudinal estimates to be similar to each other. It is not clear why the 1988 measures of speed decreased compared to 1987 and consequently caused a negative scaling relationship for the longitudinal data including those years. During May 1987, snakes were easily collected, whereas May 1988 was so cold that no active snakes were observed and only a few inactive snakes were captured during this month. Perhaps this noticeable difference in weather caused a lingering effect on individuals that were captured and tested during the rest of the 1988 season.

The cross-sectional method estimated that endurance scaled with SVL to 2.28 during 1986, whereas longitudinal estimates of this quantity with large samples ranged from 0.54 (population 1986-1987) to $3 \cdot 17$ (population 1987-1988). Presumably, the lower repeatability of endurance compared to speed caused the greater discrepancy of these endurance results compared to those for speed.

Neither cross-sectional nor longitudinal methods are immune to complications caused by yearto-year variability and differential mortality. For example, scarcity of prey could cause a decline in condition that would cause mortality or decreased performance. If there were greater mortality among individuals with slow rate of gain in performance relative to size, then a cross-sectional estimate of scaling could have a steeper slope than a mean slope computed from all the individual ontogenetic allometries. We found no such systematic deviation in scaling in this study. Mortality also represents a problem for longitudinal sampling because a slope cannot be calculated for any individual that dies before a second measurement of performance can be made. Similarly, for both cross-sectional and longitudinal methods, if environmental conditions are adverse enough to affect performance without causing mortality, one can envision ways in which either the slope or elevation of the scaling relations could be affected for both of these methods.

As Cheverud (1982) stressed, cross-sectional allometry does not indicate the ontogenetic change of a trait. Similarly, the scaling relations presented in this study indicate change in performance with some measures of size, not age. Growth of these snakes clearly is not continuous, especially 
because of hibernation. In some extreme cases we have collected snakes in the spring of one season that had no gain in length and had even lost some mass compared to late summer measurements of the preceding year. Even within an active season, we have indication of variable growth rates. For example, 70 snakes were measured twice during 1987, and a paired $t$-test revealed that the late season mass residuals were significantly greater than those of early season captures $(t=10.4$, $P<0.001)$. Thus, cessation of growth during hibernation and variable growth within times of activity clearly indicate that the detailed ontogenetic trajectories (of size and performance) within individuals are not readily modelled with simple linear or log-log equations. Furthermore, because the durations of the active season vary from year to year, it is not obvious what to use as the correct length of time for comparing rates of change among different individuals. Consequently, we chose to emphasize analysis of change in performance with size rather than change with time.

\section{Repeatability and heritability}

To date, only a few studies have dealt with the repeatability and heritability of locomotor performance of lower vertebrates. Huey \& Dunham (1987) found size-corrected speed of the lizard Sceloporus merriami at one temperature was significantly correlated with speed at other temperatures, and for individuals of this species from two natural populations maximum speed was significantly repeatable for tests one year after an initial test (intraclass correlation coefficient $t_{\text {intraclass }}=0.63, P<0.001 ; t_{\text {intraclass }}=0.56, P<0.01$ ). Van Berkum et al. (1989) calculated repeatability as Pearson's $r$ for size-corrected measures of speed and stamina of Sceloporus occidentalis at intervals ranging from two months to one year between tests. For both measures of performance, there was always significant repeatability over two-month intervals and repeatability generally declined with time (Van Berkum et al., 1989). Although sample sizes of Van Berkum et al. (1989) were small after one year, repeatability of stamina was significant $(r=0 \cdot 37, n=11, P=0.005)$ and repeatability of speed was not quite significant $(r=0.38, n=12, P=0.066)$. These studies did not find a consistent trend of speed being more or less repeatable than stamina over the same time intervals. Van Berkum et al. (1989) also used the cube root of mass divided by SVL as a condition index and this quantity was repeatable for as long as six months. For neonatal garter snakes, Thamnophis radix, Arnold \& Bennett (1988) found highly significant $(P<0.001)$ repeatability for burst speed $(r=0.60)$ and total distance crawled on a stationary surface $(r=0.55)$. For neonatal Thamnophis sirtalis from the same population as we studied, Garland (1988) found highly significant $(P<0.001)$ day-to-day repeatability for size-corrected speed $(r=0.802)$ and treadmill endurance $(r=0.696)$. These previous findings of highly significant short-term repeatability of size-corrected locomotor performance agree well with our findings (Table V). It is also apparent that relative locomotor ability (Table V; Huey \& Dunham, 1987) and indices of 'condition' (Table $V$ mass residuals; Van Berkum et al., 1989) can persist for remarkably long times of up to one year. For garter snakes, it also appears that measurements of burst speed have better repeatability than measures of endurance (Garland, 1988; Arnold \& Bennett, 1988; Table V).

For size-corrected scores of burst speed (over $50 \mathrm{~cm}$ ) and treadmill endurance $($ at $0.4 \mathrm{~km} / \mathrm{h}$ ), Garland (1988) determined 'broad-sense' heritability as twice the percentage variance component due to litter effects. Two hundred and forty-nine individual Thamnophis sirtalis from 46 litters were not fed between the time of birth and testing which occurred from 0-53 days after parturition, and single maximal values were used from four trials of speed and two trials of endurance. Garland (1988) used multiple regressions to attempt to remove as much non-genetic variance in performance as possible. For burst speed, significant independent variables in the regression were 
$\log$ (offspring SVL), $\log$ (dam SVL), $\log$ (dam mass) and (offspring age) ${ }^{2}$. For endurance, independent variables in the regression were $\log$ (offspring mass), $\log$ (offspring SVL), offspring age, (offspring age) ${ }^{2}$, and litter size. One-way ANOVA on the resulting residual performance scores revealed highly significant $(P<0.001)$ components of variance attributable to litter for both burst speed $(28.8 \%)$ and endurance $(34.8 \%)$.

The main differences between the methods of this study and those of Garland (1988) were that residual performance scores were generated from a regression using only log(offspring SVL), all snakes were tested within two days of birth, and mean performance scores were used. However, we obtained similar results with both performance residuals having a highly significant $(P<0.001)$ variance component attributable to litter, and that of burst speed $(14 \%)$ was less than that of endurance $(34 \%)$. We tested animals within two days of birth and still found very close agreement with Garland (1988) on the influence of litter effects on endurance, suggesting that age effects were adequately accounted for in Garland's analysis and were not a serious complicating factor. A finding common to both studies that remains somewhat puzzling is that the repeatability of burst speed was higher than that of endurance, and yet the litter effect on speed was less than that on endurance.

Despite the complexity and presumed plasticity of whole animal measures of performance, the present growing body of information indicates that speed and endurance can have significant longterm repeatability (up to one year) and a significant genetic component. Clearly, the rank of individuals by size-corrected performance does not persist indefinitely. Yet, given that we have captured only two individuals that have survived more than seven years in this population of Thamnophis sirtalis, one year represents a relatively large portion of an average snake's lifetime. One might also expect that considerable mortality occurs during one year for such a population. We are presently investigating whether the survivorship of snakes in this population is correlated with locomotor performance. The results of the present study suggest that the findings which would be most suggestive of natural selection will be those that relate locomotor performance to year-to-year survivorship.

\section{Summary}

Both cross-sectional and longitudinal allometric methods revealed that burst speed and endurance change significantly with the size of Thamnophis sirtalis fitchi. However, the exponent of the scaling relation of speed with SVL decreased with increased SVL of the snake (crosssectional sample, 1.6 to -0.3 ), whereas this exponent was constant for endurance (cross-sectional sample, $2 \cdot 3$ ).

There was no effect of sex on burst speed, but female snakes were significantly more massive and had significantly lower endurance than males of equal SVL. Pregnancy had a significant detrimental effect on both burst speed and endurance.

The allometric equations relating speed, endurance and mass to SVL were used to calculate sizecorrected values (residuals). These three residuals were all significantly repeatable for up to one year between measurements and analysis of neonatal snakes revealed these quantities were also significantly heritable.

Although cross-sectional and longitudinal allometries were generally similar, longitudinal allometries were highly variable depending on the years in which data were gathered. Longitudinal allometry of mass with SVL revealed some statistically significant differences attributable to the age of the snake and to the year of the study, and this may indicate that significant environmental variation caused this variability. 
We are grateful to C. Chevalier and C. Daniels for testing the 1985 cohort. J. Kaufmann assisted with field collections and performance testing during 1986 and 1987. Additional assistance in the field was provided by S. Arnold, B. Brode, F. Janzen, C. Peterson and N. Reagan. Discussions with S. Arnold, T. Garland, R. Huey, C. Peterson and P. Wainwright also were very helpful. Financial support was provided by NSF grant number BSR 8600066 to AFB.

\section{REFERENCES}

Alexander, R. McN. (1985). Body support, scaling and allometry. In Functional vertebrate morphology: 26-37. Hildebrand, M., Bramble, D. F., Liem, K. F. \& Wake, D. R. (Eds). Cambridge: Belknap Press of Harvard University Press.

Arnold, S. J. \& Bennett, A. F. (1988). Behavioural variation in natural populations. V. Morphological correlates of locomotion in the garter snake (Thammophis radix). Biol. J. Linn. Soc. 34: 175-190.

Bennet, S., McConnell, T. \& Trubatch, S. L. (1974). Quantitative analysis of the speed of snakes as a function of peg spacing. J. exp. Biol. 60: 161-I65.

Brett, J. R. \& Glass, N. R. (1973). Metabolic rates and critical swimming speeds of sockeye salmon (Oncorhynchus nerka) in relation to size and temperature. J. Fish. Res. Bd Can. 30: 379-387.

Calder, W. A., 111. (1984). Size, function, and life history. Cambridge, Mass. \& London: Harvard University Press.

Cheverud, J. M. (1982). Relationships among ontogenetic, static, and evolutionary allometry. Am. J. phys. Anthrop. 59: $139-149$.

Ford, N. B. \& Shuttlesworth, G. A. (1986). Effects of variation in food intake on locomotory performance of juvenile garter snakes. Copeia 1986: 999-1001.

Gans, C. (1974). Biomechanics: an approach to vertebrate biology. Philadelphia \& Toronto: J. B. Lippincott Co. (Reprinted by University of Michigan Press).

Garland, T., Jr. (1985). Ontogenetic and individual variation in size, shape and speed in the Australian agamid lizard Amphibolurus nuchalis. J. Zool., Lond. (A) 207: 425 439 .

Garland, T., Jr. (1988). Genetic basis of activity metabolism. 1. Inheritance of speed, stamina, and antipredator displays in the garter snake Thamnophis sirlalis. Ecolution, Lawrence, Kans. 42: 335-350.

Garland, T., Jr. \& Arnold, S. J. (1983). Effects of a full stomach on locomotory performance of juvenile garter snakes. (Thamnophis elegans). Copeia 1983: 1092-1096.

Hailey, A. \& Davies, P. M. C. (1.986). Effects of size, sex, temperature and condition on activity metabolism and defence behaviour of the viperine snake, Natrix maura. J. Zool., Lond. (A) 208: 541-558.

Heckrotte, C. (1967). Relations of body temperature, size, and crawling speed of the common garter snake, Thammophis s. sirtalis. Copeia 1967: 759-763.

Huey, R. B. \& Dunham, A. E. (1987). Repeatability of locomotor performance in natural populations of the lizard Sceloporus merriami. Evolution, Lawrence, Kans. 41: 1116-1120.

Huey, R. B. \& Hertz, P. E. (1984). Effects of body size and slope on acceleration of a lizard (Stellio stellio). J. exp. Biol. I10: $113-123$.

Huey, R. B., Schneider, W. \& Stevenson, R. D. (1981). A field portable racetrack for measuring acceleration and velocity in small cursorial animals. Experientia 37: 1356-1357.

Jayne, B. C. (1985). Swimming in constricting (Elaphe g. gutlata) and nonconstricting (Nerodia fasciata pictiventris) colubrid snakes. Copeia 1985: 195-208.

Jayne, B. C. (1986). Kinematics of terrestrial snake locomotion. Copeia 1986: 915-927.

McMahon, T. A. (1984). Muscles, reflexes, and locomotion. Princeton: Princeton University Press.

Pedley, T. J. (Ed.). (1977). Scale effects in animal locomotion. London: Academic Press.

Pough, F. H. (1978). Ontogenetic changes in endurance in water snakes (Natrix sipedon): physiological correlates and ecological consequences. Copeia 1978: 69-75.

Schmidt-Nielsen, K. (1984). Scaling. Why is animal size so important? Cambridge: Cambridge University Press.

Seigel, R. A. \& Ford, N. B. (1987). Reproductive ecology. In Snakes: ecology and evolutionary biology: 210-252. Seigel, R. A., Collins, J. T. \& Novak, S. S. (Eds). New York, Toronto \& London: Macmillan Publishing Co.

Seigel, R. A., Huggins, M. M. \& Ford, N. B. (1987). Reduction in locomotor ability as a cost of reproduction in gravid snakes. Oecologia 73: 481-485.

Sokal, R. R. \& Rohlf, F. J. (1981). Biometry. (2nd edn). San Francisco: Freeman.

Steele, R. G. D. \& Torrie, J. H. (1980). Principles and procedures of statistics: a biometrical approach. New York: McGrawHill Book Co. 
Stevenson, R. D., Peterson, C. R. \& Tsuji, J. S. (1985). The thermal dependence of locomotion, tongue flicking, digestion and oxygen consumption in the wandering garter snake. Plysiol. Zool. 58: 46-57.

Taigen, T. L. \& Pough, F. H. (1981). Activity-metabolism of the toad (Bufo americanus): ecological consequences of ontogenetic change. J. comp. Plysiol. 144: 247-252.

Taylor, C. R., Heglund, N. C. \& Maloiy, G. M. O. (1982). Energetics and mechanics of tertestrial locomotion. 1. Metabolic energy consumption as a function of speed and body size in birds and mammals. J. exp. Biol. 97: 1-21.

Van Berkum, F. H., Huey, R. B., Tsuji, J. S. \& Garland, T., Jr. (1989). Repeatability of individual differences in locomotor performance and body size during early ontogeny of the lizard Sceloporus occidemalis. Funct. Ecol. 3: 97-107.

Webb, G. J. W. \& Messel, H. (1978). Morphometric analysis of Crocodylus porosus from the north coast of Arnhem Land, Northern Australia. Aust. J. Zool. 26: 1-27. 